\title{
Health and demographic profile of boys in a metropolitan reformatory home in Western India
}

\author{
Aniruddha A. Malgaonkar ${ }^{1 *}$, Mausami A. Malgaonkar ${ }^{2}$, Kartikeyan S. ${ }^{1}$ \\ ${ }^{I}$ Department of Community Medicine, Rajiv Gandhi Medical College, Kalwa, Thane, India. \\ ${ }^{2}$ Department of Conservative Dentistry, MGM's Dental College \& Hospital, Kamothe, Navi Mumbai, India.
}

\begin{abstract}
This cross-sectional study was conducted to determine the health and demographic profile of inmates of a government-run reformatory home for boys in a metropolitan city in Western India. Inmates with more than one year of stay at the reformatory home who gave written informed consent for participating in the study were interviewed using a pre-tested semi-structured proforma wherein demographics, illness history, personal hygiene, anthropometry and medical examination were recorded. A majority of 150 inmates (mean age $14.84 \pm 0.23$ years) had previously lived in nuclear families. The mean duration of time spent outside original homes was $5.63 \pm 0.36$ years. Difference in educational profile before and after entry in reformatory school was highly significant $(p<0.001)$. Common morbidities included nutritional deficiencies, respiratory infections, eye and ear conditions, skin infections and dental caries and cavities and the delay in initiating treatment ranged from 3-7 days. Though all inmates had access to piped municipal water supply at the reformatory home, personal hygiene was found inadequate. $73.33 \%$ used tobacco, cannabis, alcohol and glue and were initiated into using addictive substances due to peer pressure, curiosity and depression. The study findings would be helpful for planning interventional measures.
\end{abstract}

Keywords: Anthropometry, Morbidity, Nutritional status, Reformatory home

\section{Introduction}

Juvenile delinquents are minors, who have committed some act that violates the law of the land. The "crimes" committed by minors are termed "delinquent acts". The Juvenile Justice (Care and Protection) Act, 2000 stipulates that a Juvenile Justice Board shall be constituted in every district, which shall consist of a Metropolitan Magistrate and two social workers, of whom at least one shall be a woman. Instead of a "trial" by a Court of Law, the accused juvenile undergoes "adjudication" by the Juvenile Justice Board, after which the accused could be sentenced in reformatories for a period of time. Reformatories are institutions for reformation, education and rehabilitation of children who are sentenced by a Juvenile Court. Inmates of reformatory homes are given education and vocational training that could be put to use after they complete their sentence. [1]

Studies have reported several determinants of delinquent behaviour - absence of marriage among parents; moral education by persons other than biological parents; [2] low socio-economic status; [2,3] overcrowded homes; [2] middle birth order; [1] substance abuse by parents; [1] low-paid parental jobs with parental absence; [2] nuclear families [4,5] strong attachment to custodial parent in single-parent families as compared to strong attachment to both parents in intact families; [6] and family arrangements other than the two-parent family home. [7] Delinquent boys tend to have low levels of social skills and are prone to indulge in cruelty to others, truancy, lying, stealing, wanton destruction and getting involved with bad friends who have similar problems. [8]

\section{Objectives}

The objective of this study was to determine the demographic and health profile of inmates in a government-run reformatory home for boys.

\section{Methodology}

This cross-sectional study was conducted in a government-run reformatory home for boys in a metropolitan city in Maharashtra state in Western India. After obtaining permissions from institutional authorities, the inmates of the reformatory home who had stayed there for more than one year were explained about the study. Those inmates who gave written informed consent for participating in the study were interviewed using a pre-tested semi-structured proforma. Demographic profile, history of morbidity and personal hygiene were recorded. Medical and dental clinical examinations were performed.

Height was measured in metres using a standard measuring tape hoisted on a vertical wall with the subject standing in erect position with his feet and head touching the wall without wearing any footwear or headwear. Weight was measured in kilograms using a pre-calibrated weighing machine, with the subject 
wearing minimal clothing. Body mass index (BMI) was calculated by dividing the body weight (in kilograms), by the square of height (in metres).

The obtained data were tabulated and statistically analysed using EpiInfo Version 7.0 (public domain software package from the Centers for Disease Control and Prevention, Atlanta, GA, USA). Continuous data were presented as Mean and Standard Deviation (SD). 95\% confidence interval (CI) was expressed in the range of (Mean - [1.96 x Standard Error]) to (Mean + [1.96 x Standard Error]). Categorical data were presented as percentage distribution. Statistical significance of difference (taken as p-value $<0.05$ ) was calculated using Karl Pearson's Chi-square test, with Mantel-Haenszel correction where applicable.

\subsection{Demographics}

\section{Results}

A total of 150 inmates of the boys' reformatory home participated in the study. Their ages ranged between 12 and 18 years with a mean age of $14.84 \pm 1.41$ years (CI: 14.61-15.07 years). A majority had lived in nuclear families before coming to the reformatory home and were Hindus by religion. (Table 1) The mean duration of time spent outside their original homes was $5.63 \pm 2.22$ years (CI: 5.27-5.98 years). More than half of respondents had not received any type of education before entering the reformatory school, while at the time of this study; all the 150 respondents had received basic schooling and vocational training. This before-and-after difference in educational profile was highly significant (Chi square value $=121.71 ; \mathrm{p}<0.001)$.

Table 1: Demographic profile $(\mathrm{n}=150)$

\begin{tabular}{|c|c|c|}
\hline \multicolumn{2}{|c|}{ Parameter } & Frequency \\
\hline \multirow[t]{3}{*}{ Age (years) } & $12-14$ & $44(29.33)$ \\
\hline & $14-16$ & $74(49.34)$ \\
\hline & $16-18$ & $32(21.33)$ \\
\hline \multirow[t]{4}{*}{ Religion } & Hindu & $124(82.66)$ \\
\hline & Muslim & $18(12.00)$ \\
\hline & Christian & $04(02.67)$ \\
\hline & Sikhs & $04(02.67)$ \\
\hline \multirow{3}{*}{$\begin{array}{l}\text { Family type (before entry in } \\
\text { reformatory home) }\end{array}$} & Joint & $18(12.00)$ \\
\hline & Nuclear & $110(73.33)$ \\
\hline & Extended Nuclear & $22(14.67)$ \\
\hline \multirow{4}{*}{$\begin{array}{l}\text { Years spent outside original } \\
\text { home }\end{array}$} & $1-3$ & $28(18.67)$ \\
\hline & $3-5$ & $24(16.00)$ \\
\hline & $5-7$ & $44(29.33)$ \\
\hline & Above 7 & $54(36.00)$ \\
\hline \multirow{3}{*}{$\begin{array}{l}\text { Education before entry in } \\
\text { reformatory home }\end{array}$} & No education & $88(58.67)$ \\
\hline & Schooling & $56(37.33)$ \\
\hline & Vocational training & $06(04.00)$ \\
\hline \multirow[t]{2}{*}{ Current educational status } & Schooling & $150(100.00)$ \\
\hline & Vocational training & $150(100.00)$ \\
\hline
\end{tabular}

Figures in parentheses indicate percentages

\subsection{Anthropometry}

As compared to their younger counterparts, the respondents in the age groups of 16-17 years and 17-18 years had a higher BMI. (Table 2)

Table 2: Anthropometry $(\mathrm{n}=150)$

\begin{tabular}{|c|c|c|c|c|c|c|}
\hline \multirow{2}{*}{$\begin{array}{c}\text { Age } \\
\text { (years) }\end{array}$} & \multicolumn{2}{|c|}{ Height (metres) } & \multicolumn{2}{c|}{ Weight (kgs.) } & \multicolumn{2}{c|}{ Body Mass Index } \\
\cline { 2 - 7 } & Mean (SD) & CI & Mean (SD) & CI & Mean (SD) & CI \\
\hline $12-13$ & $1.35(0.010)$ & $1.34-1.35$ & $31.64(0.45)$ & $31.45-31.83$ & $17.28(0.01)$ & $17.27-17.28$ \\
\hline $13-14$ & $1.41(0.008)$ & $1.40-1.41$ & $34.33(0.64)$ & $34.07-34.59$ & $17.22(0.12)$ & $17.17-17.27$ \\
\hline $14-15$ & $1.46(0.013)$ & $1.45-1.46$ & $38.18(0.67)$ & $37.97-38.39$ & $17.91(0.02)$ & $17.90-17.91$ \\
\hline $15-16$ & $1.54(0.003)$ & $1.53-1.54$ & $42.21(0.69)$ & $41.99-42.44$ & $17.76(0.06)$ & $17.74-17.78$ \\
\hline $16-17$ & $1.56(0.003)$ & $1.55-1.56$ & $46.33(0.24)$ & $46.22-46.44$ & $18.12(0.15)$ & $18.05-18.19$ \\
\hline $17-18$ & $1.58(0.003)$ & $1.57-1.58$ & $47.77(0.24)$ & $47.65-47.89$ & $19.02(0.15)$ & $18.94-19.09$ \\
\hline
\end{tabular}

$\mathrm{SD}=$ Standard deviation; $\mathrm{CI}=$ Confidence interval

\subsection{Morbidity profile}

The participants exhibited signs and symptoms of one or multiple nutritional deficiencies that included anaemia (37.33\%) and deficiencies of Vitamin A (59.33\%), Vitamin B complex (17.33\%), Vitamin C (16.67\%), and Vitamin D (5.33\%). Various morbidities comprised - respiratory infections (38.66\%), ocular conditions $(48 \%)$, otic conditions $(24 \%)$, skin infections $(10.66 \%)$, diarrhoea $(9.33 \%)$, cervical and inguinal 
lymphadenopathy $(6 \%)$, tuberculosis $(4 \%)$, helminthic infestations $(6.67 \%)$, and dental caries and cavities $(12.67 \%)$. (Table 3)The delay in initiating treatment for diseases ranged from 3-7 days with an average delay of 4 days.

Table 3: Morbidity profile

\begin{tabular}{|l|l|l|}
\hline Parameters & Urequency \\
\hline Respiratory infections & Upper respiratory tract & $38(25.33)$ \\
\cline { 2 - 3 } & Lower respiratory tract & $20(13.33)$ \\
\hline Ocular conditions & Myopia & $58(38.66)$ \\
\cline { 2 - 3 } & Other eye diseases & $12(08.00)$ \\
\cline { 2 - 3 } & Blindness (unilateral) & $02(01.34)$ \\
\hline \multirow{5}{*}{ Ear conditions } & Wax & $18(12.00)$ \\
\cline { 2 - 3 } & Otitis externa \& media & $18(12.00)$ \\
\hline \multirow{5}{*}{ Diarrhoea } & Scabies & $05(03.33)$ \\
\cline { 2 - 3 } & Pyoderma & $06(04.00)$ \\
\cline { 2 - 3 } & Fungal infections & $06(04.00)$ \\
\cline { 2 - 3 } & Leprosy & $05(03.33)$ \\
\hline Other conditions & Mucous diarrhoea & $06(04.00)$ \\
\cline { 2 - 3 } & Watery diarrhoea & $08(05.33)$ \\
\hline & Tuberculosis & $06(04.00)$ \\
\cline { 2 - 3 } & Lymphadenopathy & $09(06.00)$ \\
\cline { 2 - 3 } & Worm infestations & $10(06.67)$ \\
\cline { 2 - 3 } & Dental caries \& cavities & $19(12.67)$ \\
\hline
\end{tabular}

Some participants had multiple morbidities; Figures in parentheses indicate percentages

\subsection{Personal hygiene}

$22(14.67 \%)$ brushed their teeth on alternate days, $52(34.67 \%)$ bathed occasionally, $12(8 \%)$ did not use soap while bathing and $54(36 \%)$ washed clothes occasionally. (Table 4)

Table 4: Personal hygiene $(n=150)$

\begin{tabular}{|l|c|}
\hline \multicolumn{1}{|c|}{ Parameter } & Frequency \\
\hline Brushing teeth daily & $128(85.33)$ \\
\hline Bathing daily & $98(65.33)$ \\
\hline Use of soap while bathing & $138(92.00)$ \\
\hline Washing clothes daily & $96(64.00)$ \\
\hline Use of detergents for washing clothes & $134(89.33)$ \\
\hline Hand washing before meals & $116(77.33)$ \\
\hline Hand washing after defecation & $108(72.00)$ \\
\hline Hand washing after work & $96(64.00)$ \\
\hline
\end{tabular}

Figures in parentheses indicate percentages

\subsection{Psychosocial factors}

$51(34 \%)$ revealed a history of being subjected to frequent violence, while $99(66.0 \%)$ were exposed occasionally. 19 (12.67\%) had evidence of injuries on clinical examination. Only 40 (26.67\%) reported that they had no addictions. Of the $110(73.33 \%)$ respondents who chewed tobacco, 6 also smoked tobacco, 6 used "ganja" (cannabis), 2 consumed alcohol, and 8 sniffed glue. The reasons given for initiation into use of addictive substances were peer pressure (49.09\%), curiosity (29.09\%), and depression $(21.82 \%)$.

\subsection{Demographics}

\section{Discussion}

In this study, $82.66 \%$ were Hindus and $73.33 \%$ were from nuclear families. A Mumbai-based study [4] on institutionalised children reported that $63.5 \%$ were Hindus and $82.4 \%$ were from nuclear families. Both parents in urban nuclear families utilise much of their time and energy in providing sustenance for their family, which allows insufficient time for supervision of their children. Unsupervised children with excess freedom may get trapped in bad company and indulge in deviant behaviour. [4] Scientific advances, industrialisation and urbanisation have caused socio-cultural disruption in conventional rural lifestyles in the developing countries. Employment-driven migration from rural to urban areas has resulted in mushrooming of overcrowded urban slums resulting in social disorganization and maladjustment with lack of community support and security that was the hallmark of rural life. Owing to gradual disappearance of traditional social controls, deviant and antisocial behaviour among juveniles is increasing. Anti-social and deviant behaviour among juveniles should not 
be ignored since these may be predictors of criminal activity later in adulthood, and early interventions may help in rectifying the state of affairs. [9]

\subsection{Anthropometry}

Institution-reared children reportedly trail behind their family-reared counterparts in physical growth; retarded physical growth was found proportional to the duration of institutional care. [10] Provision of nutrients to chronically undernourished children stimulates "catch-up" growth, which may result in hormonal and metabolic changes. In the present study, the higher BMI in the age groups of 16-17 years and 17-18 years may be ascribed to "catch-up" growth. This growth spurt may be associated with early puberty and elevated gonadotropins but the underlying mechanisms are still unknown. [11] Atypical patterns of diurnal cortisol activity have been reported. [12-14] In a Ukraine-based study, non-stunted institutionally-reared children were found to have a significantly higher total daily cortisol production than both chronically stunted institutionreared children and family-reared children. [15]

\subsection{Morbidity profile}

A study [16] on Sudanese institutionalised children has reported prevalence of skin conditions (30.8\%) and helminthiasis (11.6\%), which is much higher than that reported in the present study and may be attributed to low levels of personal and food hygiene. $12.67 \%$ participants were found to have dental caries and cavities. A study [17] from Vadodara, Gujarat reported that prevalence of dental caries was higher among family-reared children $(62.12 \%)$, as compared to that in institution-reared children $(52.4 \%)$ and attributed this difference to the non-availability of sweet and sticky foods to the institutionalised children.

\subsection{Personal hygiene}

In the present study, though all participants had access to piped municipal water supply at the reformatory home, only $65.33 \%$ bathed daily. The frequency of brushing teeth daily in the present study $(85.33 \%)$ is less than the frequency $(99.4 \%)$ among institutionalised children reported by a Vadodara-based study. [17] The difference may be ascribed to non-availability of toothbrush and toothpaste and lack of awareness about dental hygiene.

\subsection{Addictions}

Alcohol and tobacco, though legally available, are considered "gateway drugs" because the addiction progresses to the use of illicit hard drugs [18] Individuals with certain characteristics are more likely to gain access to drugs. [19] A Sudan-based study [16] has reported that 54\% indulged in substance or alcohol abuse, which is lower than the frequency $(73.33 \%)$ in the present study.

\subsection{Psychosocial factors}

A Czech study on institutionalized and family-based children and adolescents reported that the level of self-regulation of behaviour and ability to control emotions was lower among institution-reared children, as compared to that in their family-reared counterparts. [20] In order to be able to live independently, institutionreared youth require constant care and support from adults who are perceived as reliable and trustworthy. [21]

\section{Conclusion}

Since the reformatory home exclusively admitted boys aged between 12 and 18 years, girls were not studied. Answers to subjective questions were as per the perceptions of the respondents and could not be verified. Due to resource constraints, laboratory investigations could not be performed. Though the educational profile improved after entry in reformatory school, most inmates had multiple morbidities, such as, nutritional deficiencies, respiratory infections, eye and ear conditions, skin infections and dental problems and their personal hygiene was inadequate. A majority used addictive substances. The findings of the study pertaining to nutritional deficiencies, morbidities, inadequacy of personal hygiene and addictions would help in planning interventional measures.

\section{References}

[1] M. Dey, Juvenile Justice in India, Int J Interdiscip Multidiscip Stud, 1(6), 2014, 64-70.

[2] F. Ngale, Family Structure and Juvenile Delinquency, Internet J Criminol, 2009; 1-19.

[3] W. S. Comanor, and L. Phillips, The impact of income and family structure on delinquency, J Appl Econ, 5, $2002,209-232$.

[4] R. Pasi, R. R. Shinde, R. S. Kembhavi, and D. D. Kadam, A cross-sectional study of the sociodemographic profile of juveniles under institutional care in the city of Mumbai, J Family Community Med, 18(2), 2011, 87-90.

[5] H. Ghattargi, and S. N. Deshmukh, Study of family background of juvenile and reasons for their admission to remand home, Indian J Community Med, 24(2), 1999, 50-57.

[6] J. H. Rankin, and R. Kern, Parental attachments and delinquency, Criminol, 32(4), 1994, 495-515. 
[7] C. L. Murry, J. Williams, and R.T. Salekin, Juvenile delinquency and family structure: Links to severity and frequency of offending, The University of Alabama McNair Journal, 2006, 87-98.

[8] C. Stevenson, and C. Larson, The Juvenile Court: Analysis and recommendation, Future of Children, 6(3), 1996, 57-59.

[9] B. R. Sharma, S. Dhillon, and Sarmadi Bano, Juvenile delinquency in India - a cause for concern, J Indian Acad Forensic Med, 31(1), 2009, 68-72.

[10] M. H. van IJzendoorn, M.J. Bakermans-Kranenburg, and F. Juffer, Plasticity of growth in height, weight and head circumference: Meta-analytic evidence of massive catch-up of children's physical growth after adoption, J Dev Behav Pediatr, 28(4), 2007, $334-343$.

[11] L. Proos, and J. Gustafsson, Is early puberty triggered by catch-up growth following undernutrition? Int J Environ Res Public Health, 9(5), 2012, 1791-1809.

[12] M. R. Gunnar, Effects of early deprivation, in C. A. Nelson, and M. Luciana (Eds.), Handbook of developmental cognitive neuroscience, (Cambridge, MA: MIT Press, 2001) 617-629.

[13] M. R. Gunnar, Early adversity and the development of stress reactivity and regulation, in C.A. Nelson (Ed.), The effects of adversity on neurobehavioral development. The Minnesota Symposia on Child Psychology. Vol. 31, (Mahwah, NJ: Lawrence Erlbaum, 2000) 163-200.

[14] M. Carlson, and F. Earls, Psychological and neuroendocrinological sequelae of early social deprivation in institutionalized children in Romania, Ann N Y Acad Sci, 807, 1997, 419-428.

[15] N. A. Dobrova-Krol, M. H. van Ijzendoorn, M. J. Bakermans-Kranenburg, C. Cyr, and F. Juffer, Physical growth delays and stress dysregulation in stunted and non-stunted Ukrainian institution-reared children. Infant Behav Dev, 31(3), $2008,539-553$.

[16] S. K. Mukhtar, M. S. K. Hashim, and A. Abdelrhman, Medical and psychosocial aspects of children in Kober and Elgeraif Reformatories, Sudan J Paediatr, 8, 2007, 147-160.

[17] Gaur, V. Katna, and S. G. Sujan, The oral health status of institutionalized children that is, Juvenile home and orphanage home run by Gujarat state Government, in Vadodara city with that of normal school children, J Indian Soc Pedod Prev Dent, 32(3), 2014, 231237.

[18] M. M. Vanyukov, R. E. Tarter, G. P. Kirillova, L. Kirisci, M. D. Reynolds, M. J. Kreek, et al., Common liability to addiction and "gateway hypothesis": Theoretical, empirical and evolutionary perspective, Drug Alcohol Depend, 123(Suppl 1), 2012, S3-17.

[19] G. P. Kirillova, M. M. Vanyukov, L. Kirisci, and M. Reynolds, Physical maturation, peer environment, and the ontogenesis of substance use disorders, Psychiatry Res, 158(1), 2008, 43-53.

[20] K. Hrbackova, and A. P. Safrankova, Self-regulation of behaviour in children and adolescents in the natural and institutional environment, Procedia Soc Behav Sci, 217, 2016, 679-687.

[21] S. Mallet, Looking backwards, moving forward: Implication for policy of a longitudinal study on youth homeless in parity, Office of Juvenile and Delinquency Prevention Bulletin, 11, 2010, 129-151. 